\title{
REFLEXÕES SOBRE SABERES NECESSÁRIOS PARA A CRIAÇÃO E COMPARTILHAMENTO DE CONHECIMENTOS DE MULHERES CAMPESINAS EM VALENÇA (BA)
}

\author{
REFLECTIONS ABOUT TO KNOW REQUIRED FOR THE CREATION AND \\ SHARING OF KNOWLEDGE OF PEASANT WOMEN IN VALENÇA (BA)
}

\section{REFLEXIONES SOBRE SABERES NECESARIOS PARA LA CREACIÓN Y COMPARTIR DE CONOCIMIENTOS DE MUJERES CAMPESINAS EN VALENÇA}

(BA)

\author{
Rubem Castro Neves ${ }^{1}$ \\ Ana Lícia de Santana Stopilha ${ }^{2}$ \\ 10.21665/2318-3888.v7n14p143-168
}

\begin{abstract}
RESUMO
A proposta deste artigo é refletir sobre os saberes necessários para a criação e compartilhamento de conhecimentos de mulheres Campesinas em Valença (BA). Esta reflexão surge das experiências vivenciadas pelos autores em pesquisa de doutorado, assim como a participação dos mesmos no Projeto de pesquisa e extensão vinculado à Universidade do Estado da Bahia - UNEB, intitulado Maria Camponesa. Os sujeitos da pesquisa são mulheres agricultoras e pescadoras do município de Valença (BA) que manejam seus saberes e práticas para garantir sua sobrevivência e perpetuação, o que revela a relevância de pesquisas dessa natureza. Sendo assim, surgiu o seguinte questionamento: quais os saberes necessários para a criação e o compartilhamento de conhecimentos entre mulheres campesinas? A metodologia utilizada para obtenção dos resultados foi a pesquisa-ação. A coleta de dados realizou-se através de questionários, rodas de conversa, oficinas para diálogo entre saberes e, especialmente, com aplicação de técnicas inerentes ao Diagnóstico Rural Participativo (DRP). Os resultados apontam até o momento que os saberes necessários para criação e difusão do conhecimento entre mulheres do campo, assumindo esse conhecimento como uma inovação, precisam ser difundidos e adotados no sistema social e a sua essência está no conhecimento cristalizado em ações e mudanças de atitudes.
\end{abstract}

Palavras-chave: Saberes. Populações Tradicionais. Campesinas. Práticas Produtivas. Difusão do Conhecimento.

\footnotetext{
1 Doutor em Difusão do Conhecimento. Professor Titular da Universidade do Estado da Bahia UNEB/Campus XIX. E-mail: rneves@uneb.br.

2 Doutora em Difusão do Conhecimento. Professora Assistente da Universidade do Estado da Bahia UNEB. E-mail: stopilha@hotmail.com.
} 


\begin{abstract}
The purpose of this article is to reflect on the knowledge necessary for the creation and sharing of knowledge of women peasants in Valença (BA). This reflection arises from the experiences of the authors in doctoral research, as well as their participation in the research project and extension linked to the State University of Bahia - UNEB, entitled Maria Camponesa. The research subjects are women farmers and fishermen from the city of Valença (BA) who manage their knowledge and practices to ensure their survival and perpetuation, which reveals the relevance of research of this nature. Thus, the following question arose: what knowledge is needed for the creation and sharing of knowledge among peasant women? The methodology used to obtain the results was the action research. The data collection was carried out through questionnaires, talk wheels, workshops for dialogue between knowledge and, especially, with the application of techniques inherent to Participatory Rural Diagnosis (DRP). The results point to the fact that the knowledge necessary to create and disseminate knowledge among rural women, assuming this knowledge as an innovation, needs to be diffused and adopted in the social system and its essence lies in knowledge crystallized in actions and changes in attitudes.
\end{abstract}

Keywords: To know. Traditional Populations. Peasants. Productive Practices. Diffusion of Knowledge.

\title{
RESUMEN
}

La propuesta de este artículo es reflexionar sobre los saberes necesarios para la creación y el intercambio de conocimientos de mujeres Campesinas en Valença (BA). Esta reflexión surge de las experiencias vivenciadas por los autores en investigación de doctorado, así como la participación de los mismos en el Proyecto de investigación y extensión vinculado a la Universidad del Estado de Bahía - UNEB, intitulado María Campesina. Los sujetos de la investigación son mujeres agricultoras y pescadoras del municipio de Valença (BA) que manejan sus saberes y prácticas para garantizar su supervivencia y perpetuación, lo que revela la relevancia de investigaciones de esa naturaleza. Siendo así, surgió el siguiente cuestionamiento: ¿cuáles son los saberes necesarios para la creación y el intercambio de conocimientos entre mujeres campesinas? La metodología utilizada para obtener los resultados fue la investigación-acción. La recolección de datos se realizó a través de cuestionarios, ruedas de conversación, talleres para diálogo entre saberes y, especialmente, con aplicación de técnicas inherentes al Diagnóstico Rural Participativo (DRP). Los resultados apuntan hasta el momento que los saberes necesarios para la creación y difusión del conocimiento entre mujeres del campo, asumiendo ese conocimiento como una innovación, necesitan ser difundidos y adoptados en el sistema social y su esencia está en el conocimiento cristalizado en acciones y cambios de actitudes.

Palabras clave: Saberes. Poblaciones Tradicionales. Campesino. Prácticas Productivas. Difusión del Conocimiento. 


\section{Introdução}

Os saberes dos indivíduos se revelam no processo de interação com o mundo e, portanto, com outros saberes. Nesse processo, os saberes encontram centralidade, reconhecendo-se que todo saber primeiro parte do próprio indivíduo e a partir daí interage com o ambiente e as outras pessoas a fim de construir sua história e seu ambiente à medida que conhece os diversos aspectos da realidade.

Entretanto, apesar dos discursos mais recentes destacarem a relevância dos saberes na construção de uma sociedade de aprendizagem inclusiva, na qual tais saberes seriam orientados para melhoria de vida das pessoas, a valorização do ser humano ainda se apresenta sob um prisma manipulativo, servindo aos interesses do capital, especialmente em grupos que praticam atividades tradicionais e que precisam manejar toda sua complexidade de cognição a fim de superar problemas oriundos da sua própria sobrevivência.

Os saberes pertencentes a grupos que praticam atividades relacionadas à natureza, e artesanais, inserem-se em um contexto que denota precariedade nas relações econômicas, sociais e políticas, alijando-as dos benefícios produzidos tanto pelos seus saberes, quanto pelos saberes oriundos da ciência. Sendo assim, tais grupos encontramse em situação de invisibilidade produzida pela racionalidade dominante e tal configuração acarreta o desperdício de experiências. Entende-se, portanto, que a mobilização dos saberes para a solução de problemas e o aprimoramento de suas práticas torna-se imprescindível.

É dentro deste contexto que se identifica a seguinte questão: quais os saberes necessários para a criação e o compartilhamento de conhecimentos entre mulheres campesinas? $\mathrm{O}$ objetivo deste artigo consiste em refletir sobre os saberes necessários para a criação e compartilhamento de conhecimentos de mulheres campesinas em Valença (BA).

As discussões contidas neste trabalho surgem das pesquisas desenvolvidas pelos autores, em nível de doutorado, no programa de Difusão do Conhecimento da Universidade Federal da Bahia, já concluído, e da participação dos mesmos no Projeto de Pesquisa e Extensão intitulado Maria Camponesa vinculado à Universidade do Estado da Bahia 
(UNEB), Campus XV, Valença (BA), desde 2016. Por se tratar de uma pesquisa-ação e por está em contínuo movimento de criação e difusão de saberes/conhecimentos, a pesquisa não apresenta dados empíricos definitivos, mas traz relatos de experiências e uma discussão do panorama teórico utilizado para a análise do grupo pesquisado.

Os sujeitos investigados são 55 mulheres de origem campesina (agricultoras de 11 zonas rurais e 2 grupos de marisqueiras) e que exercem atividades relacionadas à pesca, a exemplo da mariscagem e da agricultura familiar. A metodologia utilizada para obtenção dos resultados foi a pesquisa-ação. A coleta de dados realizou-se através de questionários, rodas de conversa, oficinas para diálogo entre saberes e, especialmente, com aplicação de técnicas inerentes ao Diagnóstico Rural Participativo (DRP).

Os resultados preliminares da articulação e compartilhamento de saberes revelaram-se nas melhorias das práticas produtivas, no domínio de novas tecnologias sociais, na conquista de novos mercados, na criação de uma Cooperativa de negócios, na identificação de canais de comunicação para difusão de conhecimentos, conferindo empoderamento e iniciativa para a mudança de atitudes.

Este artigo está dividido em seções, para melhor compreensão das reflexões, a saber: seção 1 intitulada Grupos tradicionais e campesinos: origens e conceito na qual discutem-se as origens dos grupos tradicionais e os conceitos a estes atrelados; seção 2, Mulheres campesinas: subjetividades e peculiaridades, no qual descortinam-se as subjetividades dos sujeitos deste artigo; seção 3, O saber e o conhecimento em pauta , na qual conceitua-se e traça-se as divisas entre saber e conhecimento; seção 4 Conhecimentos e saberes: nesta seção apresenta-se a difusão para a inovação e tratase o conhecimento como uma inovação com base na teoria de difusão de inovação de Everett Rogers; seção 5, Teoria da difusão de inovação: a qual reflete-se sobre o tráfego para o conhecimento e os canais de mídia de massa, os canais interpessoais e difusão de ideias e, por fim, expõem-se as considerações finais. 


\section{Grupos tradicionais e campesinos: origens e conceito}

Há cerca de dez mil anos as sociedades de caçadores e extrativistas, nômades em sua essência, realizavam atividades baseados na caça, pesca e coleta de frutos no sentido de sobreviverem. Sucederam-se as civilizações hidráulicas ou agrícolas cujo arranjo social pressupunha a proximidade entre as pessoas, sendo que a atividade produtiva era realizada pelas famílias com foco nos recursos naturais. Em ambas as sociedades, pela própria dinâmica imposta pelas relações sociais, não havia necessidade de separar espaço, tempo e lugar. A este arranjo social denominou-se chamar de sociedades précapitalistas.

As populações tradicionais exibem traços de um modo de vida não capitalista, no entanto, inseridas na dinâmica do modo de produção capitalista presente na atualidade, convivem com este sistema, ainda que às suas margens. Este fato é observado em muitas populações que exibem modos de vida que podem ser considerados tradicionais (VIANNA, 2008). Assim, a autora adota o conceito de populações tradicionais como: "participantes da formação econômica e social capitalista moderna, com todas as consequências dessa situação histórica, e não como grupos isolados, amostras 'puras' se sociedades pretéritas, como nas definições correntes, incorporadas pelo conservacionismo" (VIANNA, 2008, p. 257). Sendo assim, este conceito corrobora com a configuração de vida das Marisqueiras participantes desta pesquisa.

Dessa maneira, originalmente a estrutura social e econômica das populações tradicionais, guarda semelhança e afina-se em suas origens com o campesinato, cujas características principais revelam-se na organização social e econômica, centrada na propriedade rural familiar, tendo na agricultura sua principal fonte de sobrevivência; na vida em pequenas comunidades rurais que denotam uma cultura específica, especialmente na raiz de seus saberes provenientes da experiência; nas lutas travadas por visibilidade, constituição e construção de seu espaço socioeconômico e; na forma como estão submetidas à dominação e exploração de forças externas como o mercado. Assim, os atravessadores e o próprio Estado através de suas políticas, tornam-se agentes de dominação que qualificam tanto a forma como vivem os campesinos, quanto a de outros grupos que se encontram às margens do tecido social. Tais observações orientam 
para um conceito de campesinato que vai além das fronteiras geográficas ou profissionais, identificando-o como um modo de vida (SHANIN, 2005; WANDERLEY, 1996).

Para enfrentar o presente e preparar o futuro, o agricultor camponês recorre ao passado, que lhe permite construir um saber tradicional, transmissível aos filhos e justificar as decisões referentes à alocação dos recursos, especialmente do trabalho familiar, bem como a maneira como deverá diferir no tempo, o consumo da família. O campesinato tem, pois, uma cultura própria, que se refere a uma tradição, inspiradora, entre outras, das regras de parentesco, de herança e das formas de vida local etc. (WANDERLEY, 1996, p. 5).

A engrenagem de reprodução do capital redefiniu e colocou a seu serviço o campesinato que, embora transformado e adaptado, resistiu permanecendo identificável como tal (MOURA, 1986).

Os camponeses são marginalizados, a importância da agricultura camponesa dentro da economia nacional diminui, o crescimento mais lento de sua produção torna-a atrasada. O mesmo pode estar acontecendo com a posição dos camponeses dentro da "nação". Eles servem ao desenvolvimento capitalista em um sentido menos direto, um tipo de "acumulação primitiva" permanente, oferecendo mão-de-obra barata, alimentação barata e mercados para bens que geram lucros. Eles produzem, ainda, saudáveis e tolos soldados, policiais, criadas, cozinheiras e prostitutas; o sistema pode sempre fazer algo mais de cada um deles. E, obviamente, eles, isto é, os camponeses, dão trabalho e problemas para os estudiosos e funcionários, que quebram a cabeça em torno "da questão do seu não-desaparecimento" (SHANIN, 2005, p. 9).

Conforme sinaliza Diegues (2003), o esgotamento dos ciclos do café e do açúcar no Brasil colônia proporcionou o surgimento da pesca artesanal como alternativa de trabalho, sobrevivência e ocupação nos litorais.

[...] No período colonial, os manguezais principalmente do Nordeste e do Sudoeste foram utilizados pelas populações humanas que viviam no litoral para diversas finalidades como a extração de madeira para as construções, para a lenha, para a preparação do tanino com que se tingem as redes, para a extração de ostras, para a pesca, etc. (DIEGUES, 2001, p. 189).

Apesar de configurar-se como possibilidade econômica e social, a exemplo do campesinato, a pesca artesanal e, como categoria desta, a mariscagem, guarda profundas raízes nas atividades agrícolas constituindo no Brasil um segmento periférico, marcado por precariedades vigentes nos dias atuais e reforçadas pela égide do 
capitalismo. Vianna (2008) assevera que a discussão sobre a definição de caiçara no Brasil inclui também o pescador.

Embora diferencie a sociedade de pescadores da sociedade camponesa, especialmente aqueles grupos que exercem sua atividade no mar e que, portanto, possuem simbologias e culturas diferenciadas, Diegues (1995) admite que as pessoas que viviam em contato com o mundo natural inseriam-se na categoria de camponeses.

Conforme descreve Polany (2000), as sociedades rústicas zelam, primeiramente, pela manutenção de seus laços sociais em detrimento das atividades econômicas. $\mathrm{O}$ aspecto de imbricamento destas com as relações sociais reforçam-se a partir da realização de atividades e da divisão dos resultados de forma compartilhada. Dessa maneira, reciprocidade e generosidade tornam-se sementes para a atividade econômica.

Tais particularidades revelam um distanciamento do modo de vida produzido pelas sociedades capitalistas cuja principal motivação está baseada no lucro. Neste sentido, Gonçalves (2009) observa que a reciprocidade, a redistribuição e os laços sociais que permeiam as trocas nas sociedades denominadas "primitivas" conferem ao sistema econômico a coesão e a estabilidade social, estabelecendo uma contraposição às sociedades capitalistas industriais cujo sistema econômico é fundado na economia de mercado autorregulado que desagrega o tecido social.

[...] o modo de vida camponês é uma expressão de resistência ao processo de capitalismo e também uma forma de sobrevivência dentro do capitalismo, uma vez que a terra é utilizada também como meio de produção de bens para comercialização, mesmo com a ressalva de que o formato de produção camponesa se difere da latifundiária (capitalista por sua essência). Encontramos na economia camponesa alguns aspectos intoleráveis ao capitalismo como a troca e a reciprocidade. Portanto, a terra camponesa não é apenas terra de trabalho, ela é também morada da vida, lugar dos animais de estimação, do pomar, da horta e do jardim, é a terra da fartura, onde o grupo familiar se reproduz por meio do auto-consumo (PAULINO; ALMEIDA 2010, p. 40).

O estilo de vida camponês revelado na relação estreita com a terra, e com a construção e a difusão de um saber tradicional, também se constitui em forma de resistência ao modelo imposto pelo capitalismo. Shanin (2005) observa ainda a mobilidade presente no campesinato, que muitas vezes assume formas de trabalho diversas como estratégia 
de sobrevivência, a exemplo das marisqueiras que participaram da pesquisa referenciada neste artigo. Em época de defeso, mulheres migram para as atividades agrícolas, especialmente quando coincidem com a safra de produtos regionais como o cravo, a pimenta do reino e o dendê (medida que visa proteger os organismos aquáticos durante as fases mais críticas de seus ciclos de vida, como a época de sua reprodução). Na alta estação, quando o fluxo turístico é maior no município, assumem atividades na rede hoteleira local como faxineiras, camareiras ou cozinheiras, assim como em barracas de praia para complementar renda.

\section{Mulheres campesinas: subjetividades e peculiaridades}

Muitas são as comunidades que desenvolvem atividades produtivas tradicionais que abrigam mulheres pescadoras e agricultoras em Valença (BA). Especialmente ao longo dos anos, a divisão sexual do trabalho no setor produtivo campesino evidenciou-se. No setor pesqueiro cabia aos homens irem ao mar e às mulheres o beneficiamento do resultado da pesca e a confecção de redes e outros instrumentos para a atividade. "A pesca era uma atividade eminentemente masculina ainda que em alguns lugares a mulher participasse da puxada da rede" (DIEGUES, 1983, p.181). Assim, perpetuou-se o trabalho do homem no mar e o trabalho da mulher na terra.

\footnotetext{
Nas sociedades ocidentais, o mar permanece ainda como um espaço mal conhecido, perigoso, fora da cultura terrestre, fora da lei que impera no continente. Desse modo, desenvolveram-se duas formas de rituais, um de caráter terrestre e outro, marítimo.

Quando entram no mar, os pescadores, por exemplo, devem abandonar aquilo que vem da terra para se proteger; quando chegam do mar devem abandonar o que receberam do mar, para se reintegrar na sociedade dos continentais, sem os contaminar. Hoje, os rituais coletivos de proteção da gente do mar (procissões, oferendas, ex-votos) estão desaparecendo, mas permanecem ainda certas práticas como evitar a presença, no barco, de certas categorias de pessoas (religiosos, mulheres), não proferir certas palavras e comportamentos enquanto navegam durante a noite (DIEGUES, 2003, p. 11).
}

Conforme Woortmann Fensterseifer (1992), a divisão sexual do trabalho demarca-se, ainda na atualidade, nos espaços de atuação de homens e de mulheres. Os primeiros são responsáveis pelas atividades no mar de fora, área de oceano, enquanto as segundas 
realizam suas atividades nas praias onde se encontram as áreas de manguezais, consideradas como terra. Já nos estuários e na maré, conhecidos como mar de dentro, observa-se a participação de ambos os sexos nas atividades produtivas.

Diegues (2003) sinaliza que diversos estudiosos destacam as relações duplas entre terra e mar presentes no cotidiano dos pescadores, os quais percebem a natureza a partir destes dois mundos e organizam-se em função dos mesmos. Assim, mar e terra criam o simbolismo, o imaginário, as práticas e os saberes que permeiam a vida e as relações dos pescadores e das pescadoras.

[...] as mulheres assumem uma postura protagonista na medida em que enfrenta a barreira imposta pela divisão sexual do trabalho, que reserva aos homens o espaço público - espaço do poder - e a mulher o espaço privado - do lar e, por que não dizer, da invisibilidade - expressão máxima do patriarcado, sistema de dominação masculina na sociedade (ALBUQUERQUE; FISHER, sd).

Os modos de produzir atrelados à agricultura e à pesca artesanal, sobretudo em atividades de cunho tradicional, constituem-se em elementos culturais que revelam saberes e práticas cuja composição afina-se com a questão de gênero. Para Scott (1995), o gênero relaciona-se com a constituição das relações sociais impactando-as, considerando-se a formação de identidades, das representações sociais e da diferença entre sexos, norteando, dessa maneira, a forma como os indivíduos se organizam para lidar com os diversos aspectos da vida social. Assim, Scott (1995, p. 75) afirma que a palavra gênero "oferece um meio de distinguir a prática sexual dos papéis sexuais atribuídos às mulheres e homens".

\footnotetext{
A diferença evidente entre corpo masculino e feminino foi, primitivamente, o suporte de símbolos e mitos que a história não esqueceu em função da hegemonia da ordem racional. A cultura vem fazendo seu trabalho lapidar de reinventá-los, reatualizá-los no campo social, lugar no qual se materializam as relações desiguais entre os gêneros e destes com os recursos naturais (OLIVEIRA, 1993, p. 79).
}

Tradicionalmente, as mulheres exercem em suas comunidades um papel fundamental: aliam as atividades domésticas às atividades produtivas de extração de mariscos, semeio, plantação e coleta de frutos, confecção de utensílios para agricultura e pesca, o que permite aos homens dedicarem-se a outras lidas. Tal observação cristaliza-se nas 
palavras de Morin (2002, p. 74) quando observa sobre o modo de vida em sociedades primitivas: "os homens possuem por vezes um saber escondido às mulheres, e essas, um saber desconhecido dos homens".

A divisão sexual do trabalho está visivelmente presente, por exemplo, na mariscagem. Na comunidade de Batateira, no município de Cairú (BA), pesquisada por Esteves (2007), cabe aos homens apreenderem caranguejos visto ser uma atividade mais rentável e que exige maior força física; já as mulheres dedicam-se à extração de lambreta por ser um trabalho mais leve. Similarmente ocorre na comunidade de Mangue Seco, em Valença (BA), onde as Marisqueiras raramente apreendem caranguejos; dedicam-se, entretanto à captura de mariscos como sururu e ao beneficiamento do siri, do camarão e pescados diversos (figura 1). "Essas especializações definidas pela divisão do trabalho se fazem com base nas características físicas de força e crenças a respeito da fragilidade e vulnerabilidade das mulheres, sobretudo" (ESTEVES, 2007, p. 84).

FIGURA 1: Beneficiamento do pescado

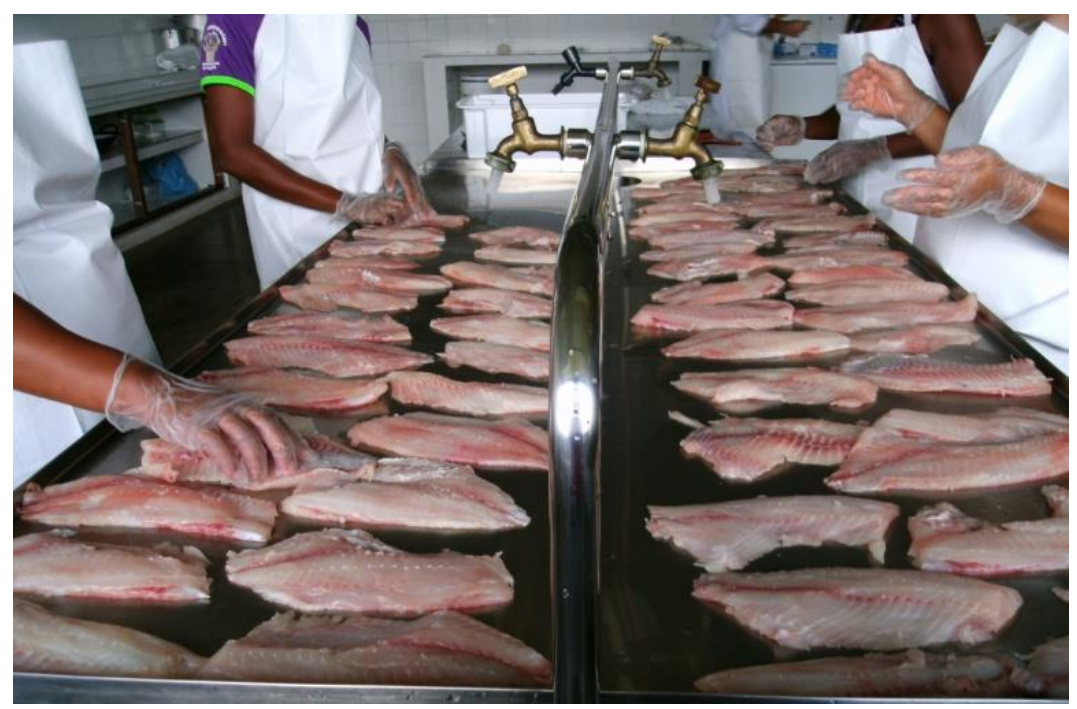

Fonte: Registro pessoal (2016) 
No imaginário da pesca, as mulheres estão presentes como sinônimos de proteção e sucesso e são reverenciadas nas figuras dos orixás.

[...] lemanjá, Oxum, Janaína, Mãe d'Água, Nanã as sereias e as rainhas do mar são "forças que moram nas águas". Donas das águas doces e do mar, são representadas por mulheres belas, vaidosas, que protegem os pescadores e mantém com estes uma relação amorosa simbólica. De tempos em tempos, transformam-se inteiramente em mulheres e cantam à beira da praia para atrair o pescador escolhido. O ciúme destas 'donas', que não suportam outra presença feminina nas suas águas, seria, pois, a causa simbólica do impedimento da mulher ir ao mar e pescar em águas distantes (OLIVEIRA, 1993, p. 78).

No entanto, enquanto a mulher mítica exerce poder e fascínio no cenário da pesca, a mulher real desdobra-se entre o produtivo e o doméstico sem, no entanto, ter o merecido reconhecimento e visibilidade, conforme sinaliza Oliveira (1993, p. 71): "À primeira todos os presentes e todos os mimos; à segunda todas as tarefas [...]". Deste modo, nas práticas produtivas, prevalecem as dicotomias homem/mulher, mar/terra, mito/real que se traduzem na "não percepção das mulheres enquanto ator social produtivo, permanecendo o mito da invisibilidade feminina [...]" (LEITÃO et al., 2009, p.11). Assim, a mulher torna-se invisível por sua condição feminina e, igualmente, por pertencer a uma camada social subalternizada.

Dessa forma, a invisibilidade da mulher campesina revela-se nos diversos aspectos da sua vida: biológico, psicológico, econômico, político, social, o que se traduz em doenças ocupacionais, baixa autoestima, baixa produtividade e lucratividade, na dificuldade de acesso às políticas públicas e vulnerabilidade social.

As mulheres campesinas, na qualidade de agricultoras familiares e de pescadoras artesanais, habitam áreas de proteção e estão associadas à aptidão do uso e do manejo de saberes e práticas aprendidas através de gerações e do trato com a natureza. Sendo assim, inscrevem-se como população tradicional embora, conforme Vianna (2008), não haja ainda um consenso sobre o termo visto que o poder público definiu população tradicional como sendo aquelas que teriam um trato diferenciado com a natureza e, portanto, estariam capacitadas para empreender a conservação ambiental. Esses grupos 
estariam autorizados a permanecer em unidades de proteção e conservação, excluindose os demais grupos.

Apesar de admitir dificuldades e ambiguidades no reconhecimento de populações tradicionais, Diegues (2001) compreende-as como aquelas cujas características relacionam-se com atividades econômicas vinculadas e dependentes da natureza, muitas vezes vivem em ecossistemas a exemplos de manguezais, restingas, florestas tropicais e sinaliza que tais populações produzem " [...] modos de vida particulares que envolvem uma grande dependência dos ciclos naturais, um conhecimento profundo dos ciclos biológicos e dos recursos naturais, tecnologias patrimoniais, simbologias, mitos e até uma linguagem específica" (DIEGUES, 2001, p. 10).

\section{O saber e o conhecimento em pauta}

Na chamada "sociedade do conhecimento", Sabbag (2007) faz uma análise da aceleração do tempo e de sua relação com as mudanças radicais envolvendo os aspectos políticos, econômicos e sociais. Segundo este autor, o maior impacto dessas mudanças está na posição e no poder exercido pelo conhecimento, sendo a formação de "massa crítica" o maior deflagrador desse processo. Sendo assim, para que haja mudanças na sociedade é preciso ter massa crítica, ou seja, um contingente de pessoas com conhecimento e atitude, suficiente para provocar a mudança.

Existem muitas classificações relacionadas ao conhecimento, uma das mais discutidas é a que o classifica como tácito e explícito. O conhecimento tácito, segundo Takeuchi e Nonaka (2008, p. 19), é aquele que "está profundamente enraizado nas ações e na experiência corporal do indivíduo, assim como nos ideais, valores ou emoções que ele incorpora", enquanto o conhecimento explícito, segundo os mesmos autores (p. 19), é aquele que "pode ser expresso em palavras, números ou sons e compartilhado na forma de dados, fórmulas científicas [...], especificação de produtos ou manuais". 
Extrai-se em Mota (2005) a delimitação entre conhecimento e saber quando esta assevera que o conhecimento é relativo a qualquer ação cognitiva que resulta na apropriação sobre causas, qualidades, estruturas, propriedades de um determinado objeto externo ao sujeito. Enquanto que o saber requer um envolvimento e uma interação mais completa entre sujeito, conhecimento e seu encadeamento com o mundo. Assim, salienta a autora:

Construir saberes significa construir "realidades da verdade". É necessário que a teoria seja dialogada com a prática. Prática, entendida aqui, não como tarefa, pois, seu significado fica empobrecido, por encontrarmos apenas "a repetição e o formalismo, a sujeição a modelos, à ausência da reflexão" (RIOS, 2001, p. 96). Entendo prática como ação que exige reflexão imaginação criadora, sensibilidade e razão associadas a um contexto [...] (MOTA, 2005, p. 44).

Para desvendar a tênue linha que faz divisa entre saber e conhecimento, Stopilha (2015) vale-se dos princípios do pensamento complexo elaborados por Morin (2005), incorporando-os à estrutura do saber em busca de sua melhor compreensão: o princípio dialógico, presente no pensamento complexo, autoriza a reflexão, partindo-se do mesmo espaço, lógicas diferentes que se complementam e se contrapõem, promovendo assim, discussão. Assim, os autores consideram que a dialogicidade promove inquietação no sujeito, conferindo-Ihe o que aponta Freire (2012, p. 131): “[...] maturidade, aventura de espírito, segurança ao perguntar, seriedade na resposta. [...]".

[...] saber torna-se alicerce na elaboração e construção do conhecimento, que se considera um domínio mais especializado que o saber. O conhecimento orienta-se para um segmento específico e tem sua construção a partir do saber do sujeito. Em um movimento dialético e cíclico, o conhecimento vai incorporar-se aos saberes do sujeito, sendo, portanto, indissociáveis. (STOPILHA, 2015, p. 54).

Reflete-se, neste sentido, se conhecimentos são descobertas e traduções daquilo que já existe. Nesta direção, Morin (2008, p. 17) questiona-se: "é um reflexo das coisas, construção do espírito, desvelamento, tradução, representação, captamos o real ou apenas a sua sombra?". Afirma ainda que o conhecimento "é necessariamente tradução, construção e solução de problema, a começar pelo problema cognitivo da adequação da construção tradutora à realidade que se trata de conhecer" (MORIN, 2008, p. 58).

Nesse sentido, se o conhecimento é ferramenta para solução de problemas, Germano (2011, p. 29) coloca "como urgente e fundamental intensificar a busca pelo diálogo entre 
o conhecimento científico e os saberes de senso comum", necessário para a criação e difusão do conhecimento entre as mulheres campesinas, alvo desta pesquisa. No entanto, acrescenta que não é uma tarefa fácil, considerando a face autoritária, determinista e fragmentada da ciência. Dessa forma, acredita o autor que as intervenções voltadas para a popularização da ciência e tecnologia só vão encontrar sentido em um novo contexto de compreensão dos diversos saberes e da própria ciência.

Sendo assim e baseado em Neves (2015, p. 71), podemos dizer que temos duas porções ínfimas no oceano das possibilidades do conhecimento: a que está ligada a experiência individual e a que se torna compartilhada através da representação. Ainda assim, Morin (2008, p.233) questiona essa representação/tradução: "se conhecemos, não diretamente as coisas, mas as suas traduções em imagens (representações) ou símbolos (ideais), nossas representações e ideais seriam sombras projetadas na parede da caverna onde estamos encerrados?". Essa é uma pergunta que Morin (2008) faz, mas ao mesmo tempo revela que isso é tudo que nós temos, sendo assim, não poderia essa sombra se constituir conhecimento?

Dessa forma, baseado nas visões de Germano (2011) e Morin (2008) com relação ao conhecimento, outras dimensões estão envolvidas e o processo cognitivo não é apenas de natureza racional. Em relação a esta pesquisa com as mulheres campesinas, quando falamos em conhecimento, estamos falando de todo processo de geração, difusão, tradução, gestão e aplicação do mesmo na vida pessoal e na comunidade em questão, encerrando um universo biológico, neurológico, psicológico, social, político, emocional, histórico, subjetivo e afetivo, em que os iguais se identificam e se juntam em torno do trabalho coletivo. Esse universo amplia assim o conceito de sociedade do conhecimento para o conceito de uma sociedade que reconheça experiências, práticas, simbologias, rituais, tradições e mitologias como aprendizado; uma sociedade mais justa, cujo conhecimento seja um valor orientado para o desenvolvimento humano.

Todo esse processo em uma comunidade dá ao conhecimento um caráter coletivo, que, de acordo com Sabbag (2007) é possível, uma vez que existem crenças compartilhadas, disseminadas e estáveis, formando a cultura de alguns povos que perduram mesmo 
sendo fruto de autoengano e, se são justificadas, homogeneizando a ação coletiva, é porque existe conhecimento coletivo.

As crenças relativas ao cotidiano das mulheres campesinas envolvem saberes que são adquiridos através das tradições de práticas produtivas das populações costeiras e ribeirinhas, na observação direta e no contato com a natureza. Descreve ainda que tais grupos são, em sua maioria, analfabetos e possuem pouco poder político.

O diálogo entre os saberes, e a experiência compartilhada das Marisqueiras e agricultoras em suas relações comunitárias, possibilitou inferir-se sobre o conceito que possuem sobre comunidade e sobre o posicionamento do mesmo neste estudo. Desta forma, além dos saberes inerentes às práticas produtivas, desvendam-se saberes que as mulheres investigadas detêm sobre suas relações sociais. Todavia, os saberes próprios de grupos e comunidades, a fim de perpetuarem-se, gerarem novos saberes e intervirem na realidade, carecem ser traduzidos a fim de dar-lhes visibilidade e atarem-se laços que possibilitem a construção de relações entre realidades distintas.

Para penetrar no tecido social, reconhecer suas rupturas e preenchê-lo, proporcionando um novo viver da pesca, do artesanato, da colheita de frutos e de outros afazeres cujo manejo de saberes se tornam imprescindível, as campesinas necessitam de oportunidades para a reelaboração de seus saberes traduzidos em modos de vida e em práticas produtivas e sociais, as quais lhes conferem a própria sobrevivência, transmutando-os em inovação, criatividade, novos saberes e conhecimentos que lhes concebam visibilidade e fortalecimento alinhados à emancipação e autonomia própria e da comunidade em que vivem.

Assim, para poder perpetuar suas práticas ao compartilhar seus saberes, tais grupos revelam solidariedade e reciprocidade no trato com suas semelhantes; existe efetivamente um trabalho coletivo, de cooperação, compartilhamento e de socialização de saberes. As mulheres assumem compartilhar saberes com destreza e paciência, guiando aquelas menos experientes a conhecerem saberes antes desconhecido. 
Neste sentido, Stopilha (2015), através da sua experiência com Marisqueiras em Valença (BA), revela:

Em uma das oficinas na qual o grupo se deslocou de canoa para um manguezal mais distante, no caminho o grupo deparou-se com outros grupos de pescadores que nos ofereceram alimento e pescados para levar. No retorno, passou-se em outra comunidade de Marisqueiras e pescadores, na qual se socializaram os pescados capturados durante o dia, trocaram-se experiências e aspirações e impressões sobre a vivência. Nestes momentos, o grupo revelou, liderados por Maria Batalha (2013), que gostaria que essas experiências acontecessem mais vezes, pois se sentiam livres, longe da violência e podiam mostrar o que sabiam e ainda levar muito alimento para casa e que também aprenderam com as comunidades com as quais interagira (STOPILHA, 2015, p. 107-108).

Sendo assim, o compartilhamento de saberes pode constituir-se em instrumento de perpetuação dos saberes tradicionais e da própria experiência social. Igualmente, surge como alternativa para grupos invisibilizados, a exemplo de mulheres campesinas, transporem os modelos hegemônicos vigentes no sentido de valorizar seus saberes e práticas subalternizados, sufocados e desperdiçados ao longo do tempo.

\begin{abstract}
Em primeiro lugar, a experiência social em todo o mundo é muito mais ampla e variada do que o que a tradição científica ou filosófica ocidental conhece e considera importante. Em segundo lugar, esta riqueza social está a ser desperdiçada. É deste desperdício que se nutrem as ideias que proclamam que não há alternativa, que a história chegou ao fim, e outras semelhantes. Em terceiro lugar, para combater o desperdício da experiência, para tornar visíveis as iniciativas e os movimentos alternativos e para lhes dar credibilidade, de pouco serve recorrer à ciência social tal como a conhecemos. No fim das contas, essa ciência é responsável por esconder ou desacreditar as alternativas. Para combater o desperdício da experiência social, não basta propor um outro tipo de ciência social. Mais do que isso, é necessário propor um modelo diferente de racionalidade (SOUSA SANTOS, 2002, p. 238).
\end{abstract}

Um aspecto importante no processo de compartilhamento de saberes é a imprescindível figura da liderança que surge espontaneamente nos grupos campesinos. As líderes naturais surgem nesse cenário motivando, articulando, incentivando grupo e assumindo a construção de pontes. Entende-se que nos referidos grupos os saberes são prioritariamente compartilhados com os familiares, os amigos e os vizinhos a quem elas reconhecem como comunidade, em um processo que envolve reciprocidade e solidariedade. Contudo, ao longo dos trabalhos realizados com os grupos, estes revelaram disponibilidade em compartilhar saberes e práticas entre si e com a equipe de pesquisadores do projeto. 


\section{Conhecimentos e saberes: a difusão para a inovação}

Este item trata o conhecimento como uma inovação com base na teoria de difusão de inovação de Everett Rogers em que é dado ênfase aos meios de difusão, ao tempo necessário para que a difusão ocorra e, ao contexto social em que está inserido o público alvo da inovação.

Uma inovação é definida por Rogers (2003), em sua teoria de difusão de inovações, como uma ideia, prática ou objeto que é percebido como novo por um indivíduo ou unidade de adoção. Não importa se a ideia já existia ou não, o que conta, na verdade, é que essa ideia seja inédita para aqueles possíveis adotantes, portanto, qualquer saber compartilhado entre as mulheres campesinas, alvo dessa pesquisa, remete o nosso objeto de pesquisa ao status de inovação.

A revisão da literatura aponta para um contexto de busca de uma educação inovadora com base na difusão de conhecimento. Tal educação envolve a dimensão humana e um novo campo de saberes, princípios e práticas, englobando, inclusive, temas mais amplos como o direito das mulheres, os conflitos étnicos, entre outros. A adoção de uma educação inovadora é diferente da adoção de um novo modelo de celular, por exemplo. Cada produto, cada serviço, cada ideia tem suas especificidades. Passa pelo crivo pessoal, pois, conforme Rogers (2003), um indivíduo pode ter informação a respeito de uma inovação, mas não ter desenvolvido ainda uma atitude favorável ou desfavorável em relação a ela.

De acordo com o Manual de Oslo, houve mudanças substanciais no desenvolvimento de políticas ligadas a inovação à medida que o entendimento sobre este assunto melhorava. Ainda segundo este Manual, a inovação pode ocorrer em qualquer setor da economia, inclusive em serviços públicos como saúde ou educação e esse "novo pensamento sobre inovação fez surgir a importância dos sistemas e levou a uma abordagem mais integrada da formulação e implantação de políticas ligadas à inovação", enfatizando a importância da transferência e da difusão de ideias, habilidades, conhecimentos e informações (ORGANIZAÇÃO DE COOPERAÇÃO E 
DESENVOLVIMENTO ECONÔMICO, 2004, p. 32). É nesse contexto que devemos considerar a difusão de saberes entre as campesinas, que tem como meta gerar tecnologias sociais e difundir ideias inovadoras a partir de informações e conhecimentos que levem à transformação individual e coletiva.

A rapidez na adoção de uma inovação, segundo Rogers (2003), está condicionada a cinco características. A primeira delas diz respeito a sua vantagem relativa, que, de acordo com o autor, é o grau com que a inovação é percebida como melhor que a ideia antecedente. A segunda ele chama de compatibilidade, definindo-a como o grau em que uma inovação é percebida como sendo compatível com os valores existentes, experiências passadas e necessidades dos potenciais adotantes. A terceira é a complexidade, que significa o grau em que uma inovação é percebida como difícil de entender e usar. A quarta característica é a possibilidade de ser testada, que representa o grau em que uma inovação pode ser experimentada. Por fim, a observabilidade como sendo o grau com que os benefícios da inovação sejam visíveis a outras pessoas (ROGERS, 2003). Apesar de essas características serem mais visíveis na inovação tecnológica, é possível na pesquisa relacionada às mulheres campesinas a visualização de duas delas: a compatibilidade e a observabilidade.

A compatibilidade, conforme Rogers (2003), se refere a uma ideia compatível ou não com os valores predominantes e as normas de um sistema social. Nesse sentido, podese observar uma perfeita identificação das mulheres com as ideias/saberes em questão: pesca, mariscagem, agricultura familiar, transformando isso em um negócio (Figura 2). 
FIGURA 2: Produto comercial

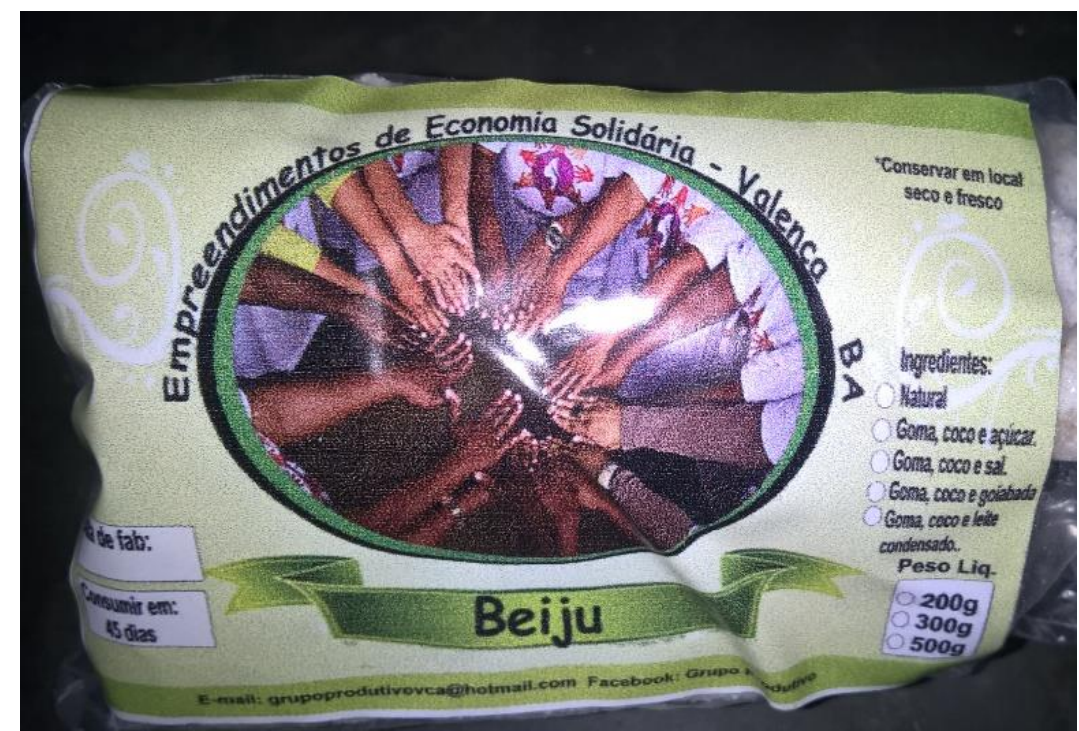

Fonte: Registro pessoal (2016)

Uma ideia incompatível não será adotada tão rapidamente quanto uma que seja compatível. A adoção de uma inovação incompatível com um sistema social muitas vezes requer a adoção prévia de um novo sistema de valores. Rogers (2003) exemplifica isso citando a utilização de contraceptivos em países onde as crenças religiosas desencorajam o uso dessas técnicas de controle de natalidade, assim como em nações muçulmanas e católicas.

Com relação a observabilidade, Rogers (2003) explica que ao tornar visíveis os benefícios, estimula-se a discussão da nova ideia de uma pessoa que adotou a inovação entre amigos e vizinhos, podendo esses pedir-lhe informações a respeito e fazer uma avaliação antes de adotar a ideia. Foi o que aconteceu entre membros da comunidade de mulheres campesinas em estudo. Os painéis solares no telhado de uma casa são altamente observáveis, conforme exemplifica Rogers (2003), o que é diferente de inovações de consumo como computadores ou fitas de vídeo, que são relativamente menos observáveis e, assim, podem difundir-se mais lentamente. Nesta pesquisa, essa característica pode estar visível para os outros na forma de benefícios conquistados por 
um indivíduo ou grupo de pessoas que se beneficiaram a partir de uma ação concretizada na prática da mariscagem, por exemplo.

\section{Teoria da difusão de inovação: o tráfego para o conhecimento}

De acordo com Rogers (2003), uma inovação para ser adotada precisa ser difundida através de canais de comunicação entre os membros de um sistema social e para isto é preciso um determinado tempo. O elemento canais de comunicação, de acordo com Rogers (2003), é o meio pelo qual as mensagens vão de um indivíduo para outro. O autor afirma que a difusão é um tipo particular de comunicação em que a informação que é trocada está preocupada com a nova ideia. A natureza da relação de troca de informações entre o par de indivíduos determina as condições em que uma fonte vai ou não vai transmitir a inovação para o receptor e o efeito da transferência. Nessa transferência, Rogers (2003) identifica os canais de mídia de massa, os canais interpessoais e de difusão de ideias.

Nesta pesquisa, prevalece os canais interpessoais, principalmente a comunicação bocaa-boca, que são os mais eficientes em persuadir o indivíduo e compartilhar a nova ideia, especialmente quando os indivíduos são próximos. A difusão de ideias, conforme Rogers (2003) ocorre mais frequentemente entre indivíduos provenientes de um mesmo sistema social, como pode ser observado entre as mulheres campesinas. Este é um princípio óbvio da comunicação humana em que a transferência de ideias ocorre mais frequentemente entre dois indivíduos que são iguais, semelhantes, ou homófilos. Homofilia, segundo Rogers (2003), é o grau em que os pares de indivíduos que interagem são semelhantes em determinadas qualidades, tais como crenças, educação, status social, e assim por diante.

Em uma situação de livre-escolha, quando um indivíduo pode interagir com outro em um universo de outros indivíduos, existe uma forte tendência para ele selecionar alguém que seja mais parecido com ele mesmo, por isso, a difusão do conhecimento entre as 
campesinas, de acordo com as observações, vem fluindo de forma espontânea e com alto grau de adoção entre as mesmas.

Rogers (2003) aponta muitas razões para isso. Relata que indivíduos semelhantes geralmente pertencem aos mesmos grupos, vivem ou trabalham perto do outro, e são atraídos pelos mesmos interesses. Esta proximidade torna a comunicação mais provável, eficaz e gratificante, posto que eles compartilham significados comuns, mútua linguagem e são semelhantes em características pessoais e sociais. Fato esse comum na comunidade estudada entre as mulheres campesinas. $O$ autor afirma ainda que a comunicação de ideias nessas condições tem maiores efeitos em termos de ganho de conhecimento, formação de atitude e mudança de comportamento.

Embora um dos problemas mais marcantes na comunicação de inovações seja o fato de que os participantes são geralmente bastante heterófilos (diferentes), Rogers (2003) salienta que a verdadeira natureza da difusão exige que pelo menos algum grau de heterofilia (diferença) esteja presente entre os dois participantes. Um agente de mudança, por exemplo, é tecnicamente mais competente do que aqueles com os quais interage para implementar a mudança, daí a importância das intervenções que têm sido feitas pela equipe de pesquisadores através dos cursos e oficinas oferecidos para as mulheres campesinas. Esta diferença leva frequentemente à comunicação ineficaz, pois não falam a mesma língua; porém, quando dois indivíduos são idênticos em relação à sua compreensão de uma inovação, a difusão pode não ocorrer porque não há nenhuma informação nova para trocar, falta conhecimento novo. O ideal então seria que os indivíduos fossem homófilos em significados comuns, linguagem, educação, características pessoais, culturais e sociais e fossem heterófilos no que diz respeito ao conhecimento da inovação. 


\section{Considerações finais}

Retomando ao questionamento deste artigo: quais os saberes necessários para a criação e o compartilhamento de conhecimentos entre mulheres campesinas? Compreende-se que os saberes revelados por indivíduos que tratam com a natureza, representados aqui pelas marisqueiras e agricultoras rurais de Valença (BA), são saberes genuínos, que não derivam de outros saberes, ao contrário, são deles constituintes. Guardam também em sua constituição aspectos do modo de vida produzido pelo grupo, da sua condição feminina e da forma como estão imbricados com o ambiente em que vivem. Sendo assim, representam a forma com que esta categoria lida com a natureza, como age e como reflete sobre seus afazeres cotidianos e suas práticas produtivas, e de como as compartilham e as perpetuam.

Ao se disponibilizarem em compartilhar saberes, as campesinas ampliaram e ressignificaram seu modelo mental e suas práticas, inovaram e promoveram a articulação de saberes, tornando-se visíveis. Depreende-se, portanto, que o saber confere ao sujeito a condição de ser e estar no mundo, de construir e ser construído em um movimento dialético. A despeito das campesinas, estes resultados podem ser observados quanto a sua maior autoestima, autonomia e empoderamento revelados nas falas e posturas nas relações sociais

Igualmente, os resultados da articulação e compartilhamento de saberes revelaram-se nas melhorias das práticas produtivas, na melhor qualidade dos produtos, no domínio de novas técnicas, na criatividade resultante em tecnologias sociais, na participação em eventos públicos solidários, na conquista de novos mercados e possibilidades de negócios que promoveram visibilidade ao grupo.

Registre-se ainda, como resultado do compartilhamento de saberes e construção de conhecimentos, a criação da Cooperativa das Mulheres da Agricultura Familiar e Economia Solidária (COOMAFES), a criação da Cantina Solidária na UNEB Campus XV e da Loja Solidária apoiada pelo Governo do Estado da Bahia, para ampliar horizontes, renda e perspectivas de melhoria das práticas produtivas, todas estão em funcionamento. 
Portanto, os saberes necessários para criação e difusão de conhecimentos entre mulheres do campo, assumindo esses conhecimentos como inovações, estão sendo difundidos e adotados, cristalizando-se em ações e mudanças de atitudes, sendo perceptível o princípio da homofilia dentro do sistema social onde essas estão inseridas, prevalecendo os canais interpessoais de comunicação no compartilhamento de novos saberes/conhecimentos, principalmente, o boca-a-boca, conforme apontam as teorias que tratam dessa questão. Outras pesquisas envolvendo processos de mobilização social e adoção de novas tecnologias aliadas à difusão de conhecimentos deverão ser feitas com este grupo brevemente.

\section{Referências}

ALBUQUERQUE, Kaio César Damasceno; FISCHER, Izaura Rufino. A mulher na pesca artesanal: discutindo gênero, divisão sexual do trabalho e conservação ambiental nos ambientes estuarinos do litoral norte pernambucano. In: Reunião anual da SBPC, 62, 2010, Natal. Anais eletrônicos. Rio Grande do Norte: SBPC/UFRN, 2010. Disponível em: <http://www.sbpcnet.org.br/livro/62ra/resumos/resumos/4688.htm>. Acesso em: 12 de nov. 2014.

DIEGUES, Antônio Carlos Santana. O mito moderno da natureza intocada. São Paulo: HUCITEC, 2001.

. Povos e mares: por uma sócio-antropologia marítima. NUPAUB-USP: São Paulo, 1995.

Pescadores, camponeses e trabalhadores do mar. São Paulo: Ática, 1983.

ESTEVES, Uliana. Saberes do mangue: relação "mulher- ambiente" na comunidade pesqueira de Batateira, Cairú-Ba. 2007. Monografia. Universidade Federal da Bahia, Escola de Filosofia e Ciências Humanas, Salvador, 2007.

FREIRE, Paulo. À sombra desta mangueira. Rio de Janeiro: Civilização Brasileira, 2012.

GERMANO, Marcelo Gomes. Uma nova ciência para um novo senso comum. Campina Grande, PB: EDUEPB, 2011. 400 p.

GONÇALVES, Alícia Ferreira. Experiências em economia solidária no estado do Ceará. Campinas: UNICAMP/CMU - Publicações; Arte Escrita, 2009. 
LEITÃO, Maria do Rosário de Fátima Andrade et al. Mulheres Pescadoras: a construção da resistência em Itapissuma. In: Intercom- Sociedade Brasileira de Estudos Interdisciplinares da Comunicação, XXXII Congresso Brasileiro de Ciências da Comunicação. Curitiba, PR- 2009.

MATURANA, Humberto; VARELA, Francisco. A árvore do conhecimento: as bases biológicas da compreensão humana. São Paulo: Palas Athena, 2001.

MORIN, Edgar. A religação dos saberes: o desafio do século XXI. Rio de Janeiro: Bertrand, 2002.

Ciência com consciência. Tradução de Maria D. Alexandre e Maria Alice. 8. ed. Rio de Janeiro: Bertrand, 2005.

O método 3: conhecimento do conhecimento. Tradução de Juremir Machado da Silva. 4. ed. Porto Alegre: Sulina, 2008. 286p.

MOTA, Ednaceli Abreu Damasceno. Saberes e conhecimentos docentes: experiências da formação e experiências da profissão. 2005. Dissertação. (Mestrado em Educação) - Faculdade de Educação, Universidade Estadual de Campinas, Campinas, 2005. 276 p.

MOURA, Margarida Maria. Camponeses. São Paulo: Ática, 1986.

NEVES, Rubem Castro. Difusão de Conhecimentos e mobilização social para adoção da política pública do Programa de Educação Ambiental e Mobilização Social em Saneamento da Bahia. 2015. Tese. (Doutorado em Difusão do Conhecimento) Faculdade de Educação, Universidade Federal da Bahia e parceiros, Salvador, 2015. 218 p.

OLIVEIRA, Neusa Maria de. (2014). Rainha das águas, dona do mangue: um estudo do trabalho feminino no meio ambiente marinho. Revista Brasileira De Estudos De População, 10(1/2), $\quad$ 71-88. Recuperado de https://www.rebep.org.br/revista/article/view/493.

ORGANIZAÇÃO DE COOPERAÇÃO E DESENVOLVIMENTO ECONÔMICO. Manual de Oslo. Rio de Janeiro: FINEP, 2004.

PAULINO, Eliane Tomiasi; ALMEIDA, Rosemeire Aparecida. Terra e território: a questão camponesa no capitalismo. São Paulo: Expressão Popular, 2010.

POLANYI, Karl. A grande transformação. As origens de nossa época. Rio de Janeiro: Elsevier, 2000.

ROGERS, Everett. M. Diffusion of innovation. 5th. edition. New York: The Free Press, 2003. 
SABBAG, Paulo Yazigi. Espirais do conhecimento: ativando indivíduos, grupos e organizações. São Paulo: Saraiva, 2007.

SCOTT, Joan. Gênero: uma categoria útil de análise histórica. Educação \& Realidade, v.IS, n.2, jul./dez. $1990 . \quad$ Disponível em: <https://www.seer.ufrgs.br/educacaoerealidade/article/viewFile/71721/40667>. Acesso em 20 de dez. 2014.

SHANIN, Teodor. A definição de camponês: conceituações e desconceituações - o velho e o novo em uma discussão marxista. Revista Nera - ano 8, n. 7 julho/dezembro, 2005.

Disponível em: <http://revista.fct.unesp.br/index.php/nera/article/view/1456/1432 > Acesso em: 05. Dez. 2014.

SOUSA SANTOS, Boaventura de. Para uma sociologia das ausências e uma sociologia das emergências. Revista Crítica de Ciências Sociais, 63, p 237-280, 2002. Disponível em:<http://dialnet.unirioja.es/servlet/articulo?codigo=1299961 >. Acesso em: 12 de jul. 2013.

(org). Produzir para viver: os caminhos da produção não capitalista. Rio de Janeiro: Civilização Brasileira, 2005.

Renovar a teoria crítica e reinventar a emancipação social. São Paulo: Boitempo, 2007.

STOPILHA, Ana Lícia de Santana. Saberes e práticas das Marias Marisqueiras da comunidade de Mangue Seco: uma investigação sobre mariscagem em Valença (BA). Tese (Doutorado em Difusão do Conhecimento) - Faculdade de Educação, Universidade Federal da Bahia e parceiros, Salvador, 2015.

NONAKA, Ikujiro; TAKEUCHI, Hirotaka. Gestão do conhecimento. Porto Alegre: Bookman, 2008.

UNIVERSIDADE DO ESTADO DA BAHIA. Projeto de pesquisa e extensão Maria Camponesa. Valença: Campus XV, 2016-2018.

VIANNA, Lucila Pinsard. De invisíveis a protagonistas: populações tradicionais e unidades de conservação. São Paulo: Annablume; FAPsESP, 2008.

WANDERLEY, Maria de Nazareth Baudel. Raízes históricas do campesinato brasileiro.In XX Encontro anual da ANPOCS. Caxambu, 1996. Disponível em: $<$ http://www.reformaagrariaemdados.org.br/sites/default/files/Ra\%C3\%ADzes\%20Histo ricas\%20do\%20Campesinato\%20Brasileiro\%20-

$\% 20$ Maria\%20de\%20Nazareth\%20Baudel\%20Wanderley\%20-\%201996.pdf>. Acesso em: 22 dez. 2014. 
WOORTMANN, Ellen Fensterseifer. Da complementaridade à dependência: espaço, tempo e gênero em comunidades pesqueiras' do Nordeste". Revista Brasileira de Ciências Sociais, n. 18, p. 41-60, 1992.

Recebido: 17.06.2019

Aprovado: 20.12.2019 